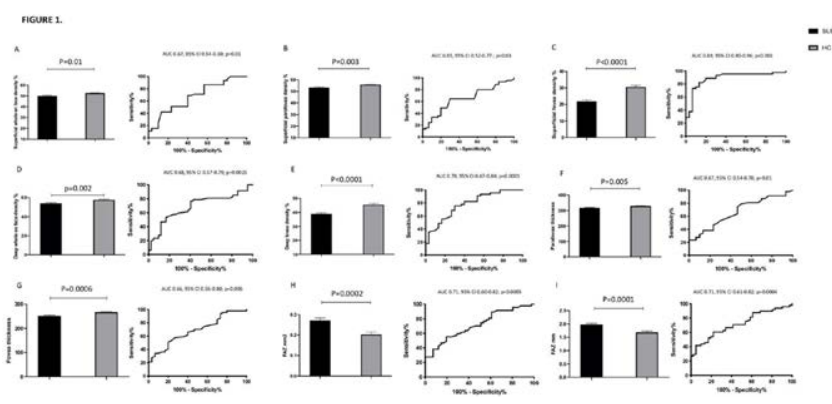

Disclosure of Interests: None declared

DOI: 10.1136/annrheumdis-2021-eular.2637

\section{POS1396 DAMAGE PROGRESSION OF FINGER JOINT CARTILAGE EVALUATED BY ULTRASOUND AND X-RAY IN PATIENTS WITH RHEUMATOID ARTHRITIS (RA)}

T. Ogura ${ }^{1}$, A. Hirata ${ }^{1}$, Y. Inoue ${ }^{1}$, T. Kagtagiri ${ }^{1}$, Y. Takakura ${ }^{1}$, H. Kameda ${ }^{1} .{ }^{1}$ Toho University, Division of Rheumatology, Department of Internal medicine, Tokyo, Japan

Background: Cartilage damage in RA has been evaluated by joint space narrowing (JSN) in X-ray, while it is not a direct evaluation of cartilage. Previously we have confirmed the usefulness of the direct imaging of finger joint cartilage by ultrasound (US) in patients with RA [1].

Objectives: We aimed to examine the temporal changes of US cartilage thickness in RA patients.

Methods: We enrolled 53 RA patients in whom the cartilage thickness of finger joints was measured by US and had radiographs of both hands at baseline and 1 -year later. The cartilage of metacapophalangeal and proximal interphalangeal joints of $2 n d$ to 5 th fingers were bilaterally visualized at the middle portion from a longitudinal dorsal view. Cartilage thickness was measured from the base of the cartilage to the interface artefact at the cartilage surface by static images. In addition, the JSN of the corresponding joints was scored using a hand X-ray by van der Heijde-modified Sharp method. Continuous variables from the two groups were analyzed using the Mann-Whitney $\mathrm{U}$ test or Wilcoxon signed-rank test. The relationships among the continuous variables were assessed using the Spearman's rank correlation coefficient.

Results: The median age of the patients was 68 years and the median disease duration was 6.3 years. The sum of total cartilage thickness from 16 joints per patient ranged from 3.1 to $9.1 \mathrm{~mm}$ (median $6.5 \mathrm{~mm}$ ) at baseline, and it was significantly correlated with total JSN score of the same joints $(\rho=-$ $0.63, p<0.001)$. The cartilage thickness was inversely correlated with disease duration (rho $=-0.40, p=0.003$ ), but not associated with age nor height. The decrease in cartilage thickness over 1 year was evident in patients with persistent moderate to high disease activity by the DAS28-CRP ( $n=10$; median
$-6.2 \%)$ as compared with other patients $(n=43$; median $-1.2 \%, p=0.004$ versus active patients)

Conclusion: This pilot study demonstrated the progression of cartilage damage by sustained RA activity, supporting the validity and usefulness of joint cartilage thickness evaluation by ultrasound in patients with RA.

REFERENCES:

[1] Ogura T, et al. Arthritis Care Res 2019 Oct 25.

Disclosure of Interests: None declared

DOI: 10.1136/annrheumdis-2021-eular.2784

\section{POS1397 HYDROXYCHLOROQUINE INDUCED RETINAL TOXICITY IN PATIENTS WITH RHEUMATIC DISEASES}

R. Maheshwari ${ }^{1}$, R. Sankaralingam2, S. Chinnadurai2, J. Antony2,

B. Chilukuri2, M. Mani2. ${ }^{1}$ Sri Ramachandra Institute of Higher Education and Research, Clinical Immunology and Rheumatology, Chennai, India;

${ }^{1}$ Sri Ramachandra Institute of Higher Education and Research, Clinical Immunology and Rheumatology, Chennai, India

Background: Retinal toxicity from hydroxychloroquine (HCQ) is rare, but the vision loss maybe irreversible and could have medicolegal consequences. Objectives: To determine the prevalence and assess the predictors of retinal toxicity due to $\mathrm{HCQ}$ in patients with rheumatic diseases. There is paucity of literature on retinal toxicity due to $\mathrm{HCQ}$ in rheumatic diseases.

Methods: A retrospective observational study was conducted in the Department of Clinical Immnuology and Rheumatology, Sri Ramachandra Institute of Higher Education and Research,Chennai, India from November 2018-May 2020, on patients taking $\mathrm{HCQ}$ for more than 6 months. All patients underwent ophthalmological screening at baseline and every 6 months, and thereafter by modern day screening methods-Humphrey Visual Field (HVF)10-2, Spectral Domain Optical Coherence Tomography(SD-OCT), except for patients with evidence of suspected retinal toxicity at baseline.Fundus autofluorescence (FAF) was done in feasible patients.

Results: 9 out of $743(1.2 \%)$ patients were identified to have retinal toxicity, detected via fundus examination ( $n=9)$, SD-OCT $(n=8 / 9)$, HVF 10-2 $(n=6 / 9)$, FAF $(n=1 / 9) .55 .5 \%(n=5 / 9)$ had Rheumatoid Arthritis(RA) and $44.4 \%(n=4 / 9)$ had Systemic Lupus Erythematosus(SLE) as their primary diagnosis. $77.7 \%(n=7 / 9)$ were females. The mean age was 47.5 years (20-72 years). $75 \%(n=3 / 4)$ of SLE patients were below 30 years of age. The average daily and cumulative dose of $\mathrm{HCQ}$ in these 9 patients were $244 \mathrm{mg}(200-400 \mathrm{mg})$ and $311.22 \mathrm{~g}(73-730 \mathrm{~g})$ respectively, whereas the mean recommended dose as per real body weight was $287.2 \mathrm{mg} /$ day. Average duration of HCQ consumption was 3.6 years (1-10 years). Only $11.1 \%(n=1 / 9)$ had presented with visual complaints of black floaters.

Conclusion: The asymptomatic nature of this irreversible toxicity, warrants frequent screening.Retinal toxicity was not age-related.Toxicity was manifested at low daily and cumulative doses.Screening should be done atleast every 6 months by fundus examination.Objective tests like HVF and SD-OCT should be done annually, especially in patients with underlying rheumatic diseases. The early manifestation of retinal toxicity in young SLE patients could have a genetic association and needs further evaluation.

Table 1. SALIENT FEATURES OF THE 9 PATIENTS PRESENTING WITH RETINAL TOXICITY DUE TO HCO

\begin{tabular}{|c|c|c|c|c|c|c|c|c|c|c|c|c|}
\hline \multirow[b]{2}{*}{$\begin{array}{l}\text { Sl. } \\
\text { No }\end{array}$} & \multirow[b]{2}{*}{ Age } & \multirow[b]{2}{*}{ Gender } & \multirow[b]{2}{*}{$\begin{array}{l}\text { Weight } \\
(\mathrm{Kg})\end{array}$} & \multirow[b]{2}{*}{$\begin{array}{l}\text { Primary } \\
\text { Diagnosis }\end{array}$} & \multicolumn{3}{|l|}{ Dose } & \multirow[b]{2}{*}{$\begin{array}{l}\text { Duration } \\
\text { (Years) }\end{array}$} & \multicolumn{4}{|l|}{ Detection Method Used } \\
\hline & & & & & $\begin{array}{l}\text { Recommended } \\
\text { Dose } \\
\text { (mg/Day) }\end{array}$ & $\begin{array}{l}\text { Received } \\
\text { Dose } \\
\text { (mg/Day) }\end{array}$ & $\begin{array}{l}\text { Cumulative } \\
\text { Dose } \\
\text { (grams) }\end{array}$ & & $\begin{array}{l}\text { FUNDUS } \\
\text { EXAM. }\end{array}$ & SD-OCT & $\begin{array}{l}\text { HVF } \\
10-2\end{array}$ & $\begin{array}{l}\mathrm{F} \\
\mathrm{AF}\end{array}$ \\
\hline 1 & 47 & $\mathrm{~F}$ & 58 & SLE & 290 & 400 & 438 & 3 & RPE Changes & Thinning/Photoreceptor Loss & Defects seen & - \\
\hline 2 & 20 & $\mathrm{~F}$ & 46 & SLE & 230 & 200 & 146 & 2 & $\begin{array}{l}\text { Multiple Small Drusens In } \\
\text { Paramacular Area }\end{array}$ & $\begin{array}{l}\text { Multiple } \\
\text { Drusens }\end{array}$ & Normal & $\begin{array}{l}\text { Perifoveal autofluo- } \\
\text { rescence spots- } \\
\text { drusens }\end{array}$ \\
\hline 3 & 23 & $\mathrm{~F}$ & 50 & SLE & 250 & 400 & 146 & 1 & RPE Changes & $\begin{array}{l}\text { RPE } \\
\text { Disruptions }\end{array}$ & Defects seen & - \\
\hline 4 & 30 & $\mathrm{~F}$ & 55 & SLE & 275 & 200 & 73 & 1 & Normal & Normal & Paracentral Scotoma & - \\
\hline 5 & 50 & $\mathrm{~F}$ & 49 & RA & 245 & 200 & 511 & 7 & $\begin{array}{r}\text { Early Bull's Eye } \\
\text { Maculopathy }\end{array}$ & $\begin{array}{l}\text { RPE } \\
\text { Atrophy }\end{array}$ & Defects seen & - \\
\hline 6 & 72 & $\mathrm{~F}$ & 60 & RA & 300 & 200 & 730 & 10 & $\begin{array}{l}\text { RPE Atrophy } \\
\text { FR Absent }\end{array}$ & $\begin{array}{l}\text { RPE } \\
\text { Atrophy }\end{array}$ & $\begin{array}{l}\text { General reduction in } \\
\text { sensitivity }\end{array}$ & - \\
\hline 7 & 65 & M & 57.4 & $\mathrm{RA}$ & 287 & 200 & 146 & 2 & RPE Changes & $\begin{array}{l}\text { RPE } \\
\text { Disruptions \& Thinning Noted }\end{array}$ & Defects seen & - \\
\hline 8 & 62 & $\mathrm{~F}$ & 70 & $\mathrm{RA}$ & 350 & 200 & 219 & 3 & Chorioretinal Atrophy & $\begin{array}{l}\text { Altered } \\
\text { RPE } \\
\text { Membrane }\end{array}$ & Defects seen & - \\
\hline 9 & 59 & M & 71.6 & $\mathrm{RA}$ & 358 & 200 & 292 & 4 & RPE Changes & $\begin{array}{l}\text { RPE } \\
\text { Disruptions }\end{array}$ & Normal & - \\
\hline
\end{tabular}

F:Female; M:Male; SLE:Systemic Lupus Erythematosus; RA: Rheumatoid Arthritis, FUNDUS EXAM.: Fundus Examination; SD-OCT:Spectral Domain-Optical Coherence Tomography, HVF 10-2:Humphrey Visual Field 10-2; FAF: Fundus Autofluorescence, RPE:Retinal Pigment Epithelium; FR:Foveal Reflex 
REFERENCES:

[1] Mortada A Abozaid et al. hydoxychloroquine retinopathy in a ohort of patients from upper Egypt.Journal of Egyptioan Ophthalmological Society 2017:110:110-113

[2] Roy AN,Samala V,Kumar YA,Fatima SS.Assessing the risk of retinopathy in Indian patients using hydroxychloroquine for rheumatic and musculoskeletal Diseases:A Retrospective Observational Study.Indian J Rheumatol 2020.

Disclosure of Interests: None declared

DOI: 10.1136/annrheumdis-2021-eular.2922

\section{POS1398 RHEUMATOLOGICAL PATIENTS PERFORMING BLOOD SELF-SAMPLING FOR DMARD THERAPY SAFETY: A PROOF OF CONCEPT STUDY COMPARING WITH VENOUS BLOOD SAMPLES}

S. A. Just ${ }^{1,2}$, P. Toftegaard ${ }^{1}$, U. Jakobsen ${ }^{3}$, T. R. Larsen ${ }^{2,3} .{ }^{1}$ Svendborg Hospital Odense University Hospital, Section of Rheumatology, Department of Medicine, Svendborg, Denmark; ${ }^{2}$ University of Southern Denmark, Department of Clinical Research, Odense, Denmark; ${ }^{3}$ Svendborg Hospital - Odense University Hospital, Department of Biochemistry, Svendborg, Denmark

Background: Regular blood sampling is a requirement for rheumatological patients receiving csDMARD, bDMARD or tsDMARD therapies (1). The frequent blood sampling affects the patient's life as they use a substantial amount of time at hospitals or by the general practitioner. Often visits are time-consuming with transport, waiting time, and for some patient's costly long travels. Giving patients the option of taking the blood samples themself in their own home, as part of a patient-centred monitoring approach, could provide the patient much higher degree of independence. Further, it may increase the quality of life, cause higher compliance with taking the control samples and possibly reduce health care costs. Objectives: 1. To investigate if rheumatological patients can take capillary blood samples and describe patient-reported outcomes (PRO) about the procedure. 2. Compare the venous and capillary samples' results. 3 . Test if the laboratory automated analysis equipment can handle the small capillary samples.

Methods: 21 rheumatological patients, underwent capillary and venous blood sampling at up to 4 occasions (1-2 months between). Instructions were available on a pictogram. PRO data were assessed by questionnaires. The patient performed blood extraction to the capillary samples from a finger after using a device making a small incision ( $2 \mathrm{~mm}$ depth and $3 \mathrm{~mm}$ width). Two capillary tubes (one Microtainer K2-EDTA and one Microtainer lithium heparin with gel) were filled with a total volume of approximately $1.0 \mathrm{~mL}$ blood. A phlebotomist took the venous sample. Blood samples were analyzed for alanine aminotransferase (ALAT), albumin, alkaline phosphatase (ALP), calcium, C-reactive protein (CRP), creatinine, potassium, lactate dehydrogenase (LDH), urate, hemolysis index, erythrocyte corpuscular volume (MCV), haemoglobin, leukocytes, differential count and platelets.

Results: A total of 53 paired capillary (C) and venous (V) samples were taken. The average perceived pain of the procedure of $C$ sampling was VAS: 10.3 (SD:14.4) (0-100) versus V sampling VAS: 8.5 (SD:11.7). 90\% of patients would accept it as a future form of blood sampling.

Differences in blood samples (C versus V) were: CRP $(-3.4 \%)$; Hemoglobin $(-1.4 \%)$; Creatinine $(-4.4 \%)$, ALAT $(-2.9 \%)$, neutrophils $(1.43 \%)$, platelets $(-16.9 \%)$. The index of hemolysis was on average $128.9 \mathrm{mg} / \mathrm{dL}$ (SD: 203) in C versus $6.7 \mathrm{mg} /$ $\mathrm{dL}$ (SD: 4.6) in V. Results was evaluated by a rheumatologist, and $92.5 \%$ of capillary samples could be used to evaluate the safety of DMARD treatment based on the most critical samples for this: ALAT, creatinine, neutrophils and platelets (1). The $7.5 \%$ not accepted were all due to aggregated platelets leading to low platelet count. There was hemolysis in $18 \%$ of the samples, but the analysis results could be used despite this. Conclusion: In the majority of rheumatological patients, capillary self-sampling is well tolerated.

We show that it is possible to extract the needed results from the capillary samples to evaluate DMARD treatment safety, despite higher hemolysis index. Using capillary samples taken at home could be a central instrument in future rheumatological patient-centred monitoring.

REFERENCES:

[1] Rigby WFC et al. Review of Routine Laboratory Monitoring for Patients with Rheumatoid Arthritis Receiving Biologic or Nonbiologic DMARDs. Int $J$ Rheumatol. 2017

Disclosure of Interests: None declared

DOI: 10.1136/annrheumdis-2021-eular.2927

\section{POS1399 \\ ALGORITHM FOR DIFFERENTIAL DIAGNOSIS OF ARTHROPATHIES USING OSTEOSCINTIGRAPHY}

E. Prokhorova ${ }^{1}$,E. Zhilyaev ${ }^{2}$, G. Zhilyaev ${ }^{3}{ }^{1}$ Main Hospital of Police, Nuclear Imaging, Moscow, Russian Federation; ${ }^{2} J S C$ European Medical Center, Medical Administration, Moscow, Russian Federation; ${ }^{3}$ Moscow State University of Medicine and Dentistry named after A.I. Evdokimov, Student, Moscow, Russian Federation
Background: Joint bone scintigraphy is a promising method for diagnosing of inflammatory joint diseases. However, its scintigraphic semiotics remains to be developed.

Objectives: To develop an algorithm for the differential diagnosis of the most common arthropathies based on quantitative osteoscintigraphy.

Methods: This single-center study included inpatients with clinical diagnoses of rheumatoid arthritis (RA), axial spondyloarthritis (including ankylosing spondylitis - aSPA), peripheral spondyloarthritis (including reactive arthritis - $\mathrm{pSpA}$ ), psoriatic arthritis (PsA), and osteoarthritis (OA) established by a rheumatologist and meeting the relevant criteria, Three hours after the injection of pyrophosphate, labeled with Tc-99m, scintigraphy of the skeletal bones was carried out according to the "whole body" program. The joint / bone accumulation ratio (AR) was calculated as the ratios of counts in relevant areas. All AR were recalculated into T-score for each joint based on data from control group. The CHAID algorithm for classification trees constructing was used. The significance of the division in the nodes was estimated with Bonferroni adjustment.

Results: 266 patients were included in the study aged $46.6 \pm 14.3$ years, men $134(50.4 \%)$. aSPA was diagnosed in 40 patients, pSpA in 87, RA in 45, OA in 68 , PsA in 26. 2279 joints were analyzed. A classification tree for differential diagnosis of arthropathies has been built (Pict.). Key indicators for identifying subgroups in the algorithm: AR in the wrist, knee and hip joints.

At the first step of the classification tree, the sum of the T-scores of the wrist joints is determined. If this amount exceeds 7.76 (node 2), the most likely diagnosis is RA ( $58.5 \%$ of patients in the subgroup of this node). Patients with the sum of the T-scores in the wrist joints less than 7.76 (node 1), in turn, were divided depending on the sum of the T-scores of hip joints. Those with this value less than 3.25 (node 3), mainly suffered from OA (48.7\%), less often in this subgroup were diagnosed pSpA $(16.7 \%)$ and PsA (14.1\%). Patients in whom the sum of the T-score in the hips was more than 3.245 (node 4) were further subdivided depending on the sum of the T-scores in the shoulder joints. If it was more than 4.21 (node 8 ), then pSpA was most likely $(58.7 \%)$. If the sum of the T-scores of the shoulder joints was in the range from 2.05 to 4.21 (node 7 ), then these are mainly patients with spondyloarthritides $(56.2 \%$ with aSPA and $31.2 \%$ with $\mathrm{pSpA}$ ) and a small number of patients (10\%) with PsA. In the subgroup with the sum of T-scores of the shoulder joints $<2.05$ (node 6), patients with PSA (40\%) prevailed, with a significant proportion of persons with OA (27.5\%). Thus, out of the final branches formed by the tree (node 2, 3, nodes 6-8), four correspond to certain diseases (node 2 - PA, node 3 - OA, node 7 - aSPA, node 8 - pSpA). Node 6 includes patients with various diseases with a predominance of PsA. The level of significance of differences between the formed groups at all branch points of the tree is $p=0.001$ or less (Bonferroni adjusted). In the training sample, $51.5 \%$ of observations are correctly classified. According to cross-validation data, the expected rate of correct classifications in real application of the algorithm is $38.0 \%$.

Conclusion: An algorithm for the differential diagnosis of the most common inflammatory diseases of the joints has been developed, which makes it possible to use the data of quantitative osteoscintigraphy in the process of diagnosing arthritis.

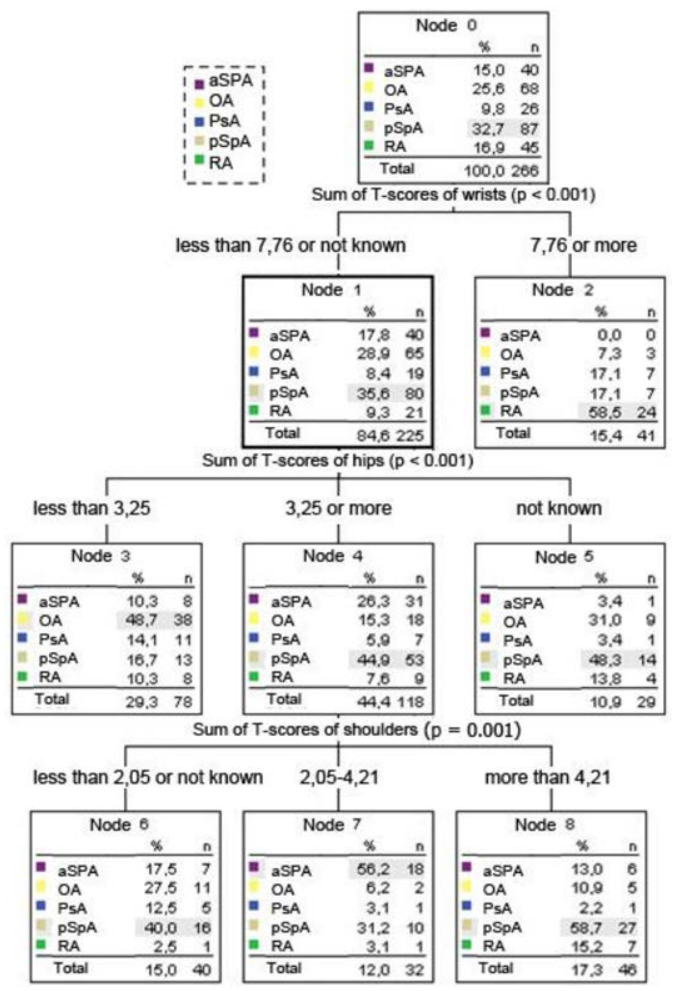

